cited, fail to show any deficiency of this enzyme in leukemic cells and the elevated UDPG in myeloid leukemic cells remains unexplained. There appeared to be no correlation with therapy or differential count, although in two cases of chronic myelocytic leukemia studied prior to, and during treatment, there was an increase of the specific activity.

This work was supported by the Veterans Administration and U.S. Public Health Service grant CA-07 I69-or from the National Cancer Institute.

Research Division, Veterans Administration, GEORGE S. NAKAI Los Angeles, Calif. and

Dept. of Medicine, U.C.L.A. Center for the Health Sciences, Charles G. Craddock Los Angeles, Calif. (U.S.A.)

r G. S. Nakai and C. G. Craddock, Cancer Res., 25 (I965) 575.

2 L. F. Leloir and S. H. Goldemberg, in S. P. Colowick and N. O. Kaplan, Methods in Enzymology, Vol. 5, Academic Press, New York, I962, p. I45.

3 O. H. Lowry, N. J. Rosebrough, A. L. Farr and R. J. Randall, J. Biol. Chem., I93 (I95I) 265.

4 J. S. Johnson and R. M. Fusaro, Anal. Biochem., 7 (I964) I89.

5 W. L. Miller and C. VanderWende, Biochim. Biophys. Acta, 77 (I963) 494.

6 A. A. Yunis And G. K. Arimura, Cancer Res., 24 (I964) 489.

7 A. Lisker, J. I. Brody and L. H. Beizer, Clin. Res., I3 (1965) 278.

Received January Ioth, I966

" Present address: Division of Biology, California Institute of Technology, Pasadena, Calif., U.S.A. (9I IO9)

Biochim. Biophys. Acta, I2I (1966) 195-197

BBA 23238

\title{
Interaction of concanavalin A, a phytohemagglutinin, with model substrates
}

Plant agglutinins, also referred to as phytohemagglutinins and lectins ${ }^{1}$, have been widely applied as reagents for typing blood ${ }^{2}$, examining the nature of the carbohydrate residues responsible for blood-group specificity ${ }^{3}$ and separating Type $A$ from Type $O$ cells. Besides agglutinating the erythrocytes of certain species, one of these plant proteins, concanavalin A (refs. 4-6), also forms a precipitate with a variety of related polysaccharides including glycogens ${ }^{5-9}$, amylopectins ${ }^{9}$, dextrans ${ }^{9}, 10$, and yeast mannans ${ }^{9,11,12}$.

From a study of the relationship of polysaccharide structure to the extent of interaction with concanavalin A (ref. 9) using both turbidimetric and agar-gel diffusion procedure ${ }^{13}$, it was concluded that only branched polysaccharides containing terminal non-reducing $\alpha$-D-glucopyranosyl or $\alpha$-D-mannopyranosyl residues formed a precipitate with this protein ${ }^{9}$. Mono- and oligosaccharides and modified sugars were found to inhibit competitively the precipitation reaction between concanavalin $\mathrm{A}$ and polysaccharides ${ }^{14}$, leading the authors to conclude that unmodified hydroxyl groups at $\mathrm{C}-3, \mathrm{C}-4$, and $\mathrm{C}-6$ of the $\mathrm{D}$-arabino-hexopyranosyl ring system were necessary for interaction with the protein ${ }^{14}$. Compounds with the $\alpha$-anomeric configuration were good 
inhibitors whereas the corresponding $\beta$-anomers were very poor or non-inhibitors. More recently it was reported that certain levans also form a precipitate with concanavalin A (ref. I3). This was rationalized on the basis of common configurational features, namely that the hydroxyl groups at $\mathrm{C}-3, \mathrm{C}-4$, and $\mathrm{C}-5$ of $\beta$-D-fructofuranosyl residues and $\alpha$-D-glucopyranosyl units are of the same configuration despite the different ring systems.

Although homopolymers, the polysaccharides cited above are polydisperse and contain various types of glycosidic linkages. This complexity makes interpretation of polysaccharide-concanavalin A interaction difficult. It was decided to use model compounds in order to confirm the above conclusions and to demonstrate that these interactions are specific and analogous in many respects to the antibody -antigen system.

Formation of a three-dimensional lattice, (believed to be a prerequisite for the formation of a precipitate between polysaccharide and concanavalin A) appears unlikely with univalent haptens. (See, however, KolEckI And Springer ${ }^{15}$.) However, by coupling univalent haptens through covalent linkages to an inert macromolecule (for example, by coupling p-aminophenyl glycosides to protein) it is possible to produce a multivalent antigen. Such conjugates, provide a unique system for controlling the nature and number of the mono- and oligosaccharide residues introduced. These model substances also allow quantitative study of the reaction and permit determination of the composition of the resultant precipitate by estimating the total nitrogen and carbohydrate content.

The $p$-aminophenyl- $\beta$-glycosides of D-glucose, D-galactose, 2-acetamido-2-deoxyD-glucose, maltose, cellobiose, gentiobiose and lactose, and the $p$-aminophenyl$\alpha$-glycosides of $\mathrm{D}$-glucose, D-mannose and $\mathrm{L}$-fucose were synthesized and coupled by diazotization to bovine serum albumin, using standard procedures. The carbohydrate content of the conjugates was determined by the anthrone method. (2-acetamido2-deoxy-D-glucose was determined by a modification of the Elson-Morgan method.)

The reactivity of the carbohydrate-protein conjugates was examined using both a precipitation procedure and two dimensional immunodiffusion in agar gel13;

TABLE I

PRECIPITATE FORMATION OF PROTEIN-CARBOHYDRATE CONJUGATES WITH CONCANAVALIN A

\begin{tabular}{|c|c|c|c|}
\hline Nature of sugar moiety & $\begin{array}{l}\text { Number of sugar } \\
\text { residues per mole of } \\
\text { bowine serum albumin }\end{array}$ & $\begin{array}{l}\text { Reactivity of conjugates } \\
\text { ( } T \mathrm{mg} \text { and } 5 \text { mg/ml) } \\
\text { with concanavalin } A \\
\text { (ro } \mathrm{mg} / \mathrm{ml} \text { ) }\end{array}$ & $\begin{array}{l}\text { Precipi- } \\
\text { tation band } \\
\text { in agar gel }\end{array}$ \\
\hline
\end{tabular}

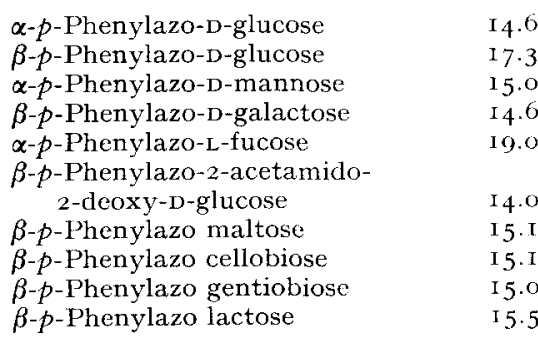

14.6

$7 \cdot 3$

5.0

4.6

19.0

I 4.0

$15 . \mathrm{T}$

5.I

I 5.5

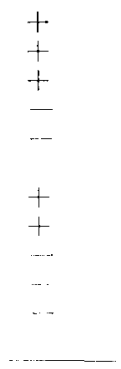


results from both techniques were comparable. The phenylazo conjugates containing the monosaccharides D-glucose, D-mannose and 2-acetamido-2-deoxy-D-glucose and the dissaccharide maltose all gave distinct precipitation bands when allowed to diffuse toward concanavalin A. All other carbohydrate-protein conjugates failed to react. (See Table I.) When the diffusion plates were rinsed with dilute saline and layered with a solution of methyl $\alpha$-D-mannopyranoside ( $10 \mathrm{mg} / \mathrm{ml}$ ) (an excellent inhibitor of concanavalin A-polysaccharide interaction) $)^{14}$, the precipitation bands disappeared leaving only the faint orange color of the azo carbohydrate-protein conjugate which remained at the site of the original band. The bands disappeared in the order 2 -acetamido-2-deoxy-D-glucose conjugate (I $5 \mathrm{~min}$ ); $\alpha$ - and $\beta$-phenylazo-D-glucose (20 $\mathrm{min}$ ), maltose (40 min), D-mannose (300 min). This confirms our previous observations ${ }^{13,14}$ regarding the binding affinity of these sugars, namely that the $\alpha$-glycoside of D-mannose is bound most strongly followed by maltose, etc.

Qualitative precipitation tests were performed by adding concanavalin A ( $\mathrm{rml}$ containing Io mg of partially purified protein) to two concentrations of conjugate ( $\mathrm{I} \mathrm{ml}$ containing $5 \mathrm{mg}$ and I $\mathrm{mg}$ carbohydrate-protein conjugate) so as to insure an excess of concanavalin $\mathrm{A}$. The reaction mixtures were stirred and allowed to stand at room temperature $\left(25^{\circ}\right)$ overnight. Immediate precipitation occurred in the case of the $\mathrm{D}$-mannose, $\mathrm{D}$-glucose ( $\alpha$ - and $\beta$-phenylazo), 2 -acetamido-2-deoxy-D-glucose and maltose conjugates; however, the D-galactose, L-fucose, cellobiose, gentiobiose, and lactose conjugates gave no precipitate, even after standing several weeks at $3^{\circ}$. Quantitative precipitation studies to obtain more definitive information on the nature of the interaction are now in progress.

The specificity of the interaction was further demonstrated by examining the action of various mono- and disaccharides on the precipitates formed above. At a concentration of Io $\mathrm{mg} / \mathrm{ml}$, I $\mathrm{ml}$ of solutions of D-galactose, melibiose, cellobiose and lactose had no effect, whereas maltose or methyl $\alpha$-D-mannopyranoside, even in much lower concentration, rapidly and completely dissolved the precipitates in agreement with previous studies ${ }^{13,14}$.

The lack of reactivity of concanavalin $\mathrm{A}$ with bovine serum albumin itself, as well as with the D-galactose, L-fucose, lactose, cellobiose, and gentiobiose conjugates, suggests that the interaction of the carbohydrate-protein conjugate with concanavalin $A$ is specific and is dependent upon both the nature and anomeric configuration of the sugar moiety. Comparison of the data on the maltose and cellobiose protein conjugates indicates that an $\alpha$-D-glucopyranosidic residue is required for the formation of a precipitate since these sugars differ only in the anomeric nature of the glucosidic bond linking the two glucopyranosyl residues. These studies further suggest that branch points (such as occurs in glycogen) are not receptor sites necessary for precipitate formation with concanavalin $\mathrm{A}$, a requirement proposed by previous workers ${ }^{7,8}$.

The fact that the $\beta$-p-phenylazo-D-glucose conjugate is highly reactive in the concanavalin A system was unexpected. Earlier inhibition studies ${ }^{\mathbf{1 4}}$ showed that methyl $\alpha$-D-glucopyranoside is a very good inhibitor of the concanavalin $\mathrm{A}$-dextran system, whereas methyl $\beta$-D-glucopyranoside is a poor inhibitor. Recently phenyl $\beta$-D-glucopyranoside and its $p$-nitrophenyl analogue were found to be relatively good inhibitors, indicating that the aromatic aglycone may change the conformation of the glucosyl residue rendering it more complementary to the concanavalin A binding site; or more likely, that non-specific binding of the aromatic phenyl group occurs, 
probably to a corresponding hydrophobic region of the protein in close proximity to the carbohydrate-binding region. This finding is analogous to several different systems ${ }^{16,17}$ observed by investigators employing the hapten-inhibition technique. The greater affinity which certain glycosidases display toward glycosides containing aromatic aglycones may also be cited ${ }^{18}$. Therefore it is not surprising that the $\beta$-p-phenylazo-D-glucose-bovine serum albumin conjugate forms a precipitate with concanavalin $\mathrm{A}$. The same reasoning may also be applied to the $\beta$-p-phenylazo-2-acetamido2-deoxy-D-glucose conjugate.

In addition to specific homopolysaccharides, concanavalin A will form precipitates with more complex biopolymers as long as they contain the proper determinant carbohydrate residues as non-reducing end units. These include certain lipopolysaccharides $^{19}$, pneumococcal polysaccharides ${ }^{19}$, phosphomannans $^{19}$ and also various glycoproteins ${ }^{19}$. Other investigators have reported that concanavalin A forms a precipitate with serum proteins ${ }^{20,21}$. (See also R. MONTGOMERY, private communication.) We now believe it is justified to conclude that it is the specific carbohydrate residues of these biopolymers with which concanavalin A interacts. Thus, concanavalin A may be considered as a specific protein reagent for the detection and preliminary characterization of certain specific carbohydrate-containing biopolymers.

This work was supported by National Institutes of Health research grants. One of us (I. J.G.) is an established investigator of the American Heart Association. Part of these studies was carried out at the Department of Biochemistry, State University of New York at Buffalo.

Department of Biological Chemistry,

I. J. GOLDSTEIN

The University of Michigan,

R. N. IYEK

Ann Arbor, Mich. (U.S.A.)

I W. C. Boyd and E. Shapleigh, Science, i I9 (I954) 49.

2 W. C. BOYd, Vox Sanguinis, 8 (1963) 1.

3 W. T. J. Morgan and W. M. Watkins, Brit. J. Exptl. Pathol., 34 (1953) 94.

4 J. B. Sumner, J. Biol. Chem., 37 (IgI9) I37.

5 J. B. Sumner and S. F. Howeld, J. Bacteriol., 32 (1936) 227.

6 J. B. Sumner and S. F. Howell, J. Biol. Chem., i I 5 (1936) 583.

7 J. A. Cifonelli, R. Montgomery and F. Smith, J.Am. Chem. Soc., 78 (1956) 2485

8 D. J. Manners AND A. Wright, J. Chem. Soc., (I962) 4592.

9 I. J. Goldstein, C. E. Hollerman and J. M. Mrrrick, Biochim. Biophys. Acta, $97(1905) 68$.

io J. A. Cifonelli, B. A. Lewis, R. Montgomery and F. Smith, Am. Chem. Soc. Abstr., i29 (1956) $3 \mathrm{D}$.

I I. B. SUmner ANd D. J. O'Kane, Enzymologia, I 2 (1948) 25 I.

I2 J. A. Cifonelli and F. Smith, Anal. Chem., 27 (I955) I639.

13 I. J. Goldstein and L. So, Arch. Biochem. Biophys., I I I (I965) 407.

I 4 I. J. Goldstein, C. E. Hollerman and E. E. Smith, Biochemistry, 4 (Ig65) 876.

15 B. J. Kolecki and G. F. Springer, Federation Proc., 24 (1965) 63 I.

I6 G. F. Springer, P. R. Desai and B. J. Kolecki, Biochemistry, 3 (1964) Io76.

I 7 S. W. Tanenbaum, G. C. Burke and S. M. Beiser, Biochim. Biophys. Acta, 54 (1961) 439.

I8 R. L. Nath and H. N. Rypon, Biochem. J., 57 (I954) I.

ig I. J. Goldstein and L. L. So, to be published.

20 H. Harris and E. B. Robson, Vox Sanguinis, 8 (1963) 348.

21 S. Nakamura, K. Tanaka and S. Murakawa, Natuve, I88 (Ig60) I 44.

Received February 3rd, Ig66 